\title{
Differentiation of the Isomers of $N$-Alkylated Cathinones by GC-EI-MS-MS and LC-PDA
}

\author{
Erina Kohyama,*† Takao ChIKumoto, ${ }^{*}$ Hiroyuki Tada,* Kiyoyuki KitaichI, $* *$ Tadashi HoriuchI,* \\ and Tetsuro ITO $* * * \dagger$ \\ *Gifu Prefectural Research Institute for Health and Environmental Sciences, Naka-fudogaoka, Kakamigahara, \\ Gifu 504-0838, Japan \\ **Gifu Pharmaceutical University, 1-25-4 Daigaku-nishi, Gifu 501-1196, Japan
}

\begin{abstract}
Synthetic compounds structurally derived from the mild stimulant 2-amino-1-phenyl-1-propanone, known as cathinone derivatives, are one of the largest growing class of synthetic designer drugs. The characterization of these drugs is complicated by the structural diversity and similarity of compounds in the ever-growing cathinone family. This paper demonstrates the successful application of gas chromatography-electron ionization-tandem mass spectrometry (GC-EIMS-MS) and liquid chromatography-photodiode array (LC-PDA) analysis to differentiate structurally similar derivatives including regioisomers of cathinones. Product ion spectrometry of iminium ions allows for an univocal differentiation of the studied cathinones with the same aminoalkyl moiety. Furthermore, the product ion spectrometry of acylium ions and ultraviolet spectra obtained by LC-PDA enabled differentiation of regioisomers resulting from different substitution patterns on the aromatic ring. The validity of the method was demonstrated by the analysis of $\mathrm{N}$-alkylated ortho-, meta-, and para-alkylcathinones along with the scaffolds of buphedrones and pentiophenones.
\end{abstract}

Keywords Cathinone, legal high, GC-EI-MS-MS, LC-PDA, structural differentiation, iminium ion, collision-induced dissociation

(Received December 22, 2015; Accepted April 19, 2016; Published August 10, 2016)

\section{Introduction}

The surge in abuse of psychoactive designer drugs has become a social problem; considerable attention has been focused on two major classes of derivatives, synthetic cathinones and synthetic cannabinoids. ${ }^{1-3}$ The former are chemicals that are reported to stimulate the central nervous system with amphetamine-like psychoactive effects. ${ }^{46}$ They form a large family of compounds produced by substitutions at three locations of the parent molecule cathinone..$^{7-9}$ Synthetic cathinones seem to occupy a growing market position, and the lists of scheduled drugs have recently been revised and updated in many countries, including Japan (Designated Substances (Shitei-Yakubutsu) under the Pharmaceutical Affairs Law of Japan), to prevent the expansion of newly developed cathinones. Despite efforts to eliminate illicit drugs, the growing number of structurally modified derivatives has continuously provided new drugs, and governmental authorities are now faced with a tiresome "cat-and-mouse" game. Specific synthetic cathinones along with some of their possible analogues (e.g., analogues of (S)-2-amino-1-phenyl-1-propanone, which have particular substituents on amino group, propanone terminus, and phenyl

† To whom correspondence should be addressed.

E-mail: koyama-erina@pref.gifu.lg.jp (E. K.); ito-tetsuro@pref. gifu.lg.jp, teito@gifu-pu.ac.jp (T. I.)

T. H. present address: Gifu Prefectural Tajimi Hospital, 5-161 Maebatacho, Tajimi, Gifu 507-8522, Japan. ring) are regulated by law in Japan.

The accurate and rapid identification of a wide variety of such drugs with the ability to differentiate structurally similar derivatives, including regioisomers, represents an ongoing challenge to forensic toxicologists. When similar physicochemical properties of isomers are considered, authentic standards of each isomer are required for differentiation by chromatographic separation. However, limited availability of such standards is inevitable. Conversely, an understanding of the mass spectral properties is required for acquiring structural information and exact discriminations of isomers.

Gas chromatography-mass spectrometry (GC-MS) and liquid chromatography-mass spectrometry (LC-MS) are necessary for the screening of compounds in illicit drug products. ${ }^{7,810-18}$ The LC-MS spectrum provides a clue about the molecular weight, and the GC-MS spectrum generally gives structural information about the molecule. However, they are insufficient for discriminating between isomeric cathinone derivatives. Alternatively, the electron ionization (EI) mass spectra of cathinones show intense base peak ions (the iminium ion) at low masses, generated by the first $\alpha$-cleavage reaction and accompanied by a few fragment ions with very low abundance. ${ }^{12,13}$ Thus, product ion spectrometry using GC-MSMS is one of the most promising tools for obtaining additional structural information for the identification of a wide range of synthetic cathinones with high sensitivity and reproducibility. Among the various techniques, GC-MS-MS is especially useful due to its simple procedures for maintenance and costeffectiveness, as compared to liquid chromatography-tandem 
mass spectrometry (LC-MS-MS). A recent study reported the effectiveness of GC-MS-MS in discriminating regioisomers of aromatic ring-substituted fluorophenethylamines and fluorocathinones. ${ }^{10,11}$ They combined EI-MS-MS and chemical ionization (CI)-MS-MS, which allowed for regioisomeric differentiation. However, their procedure is limited to fluorocathinones, and is not available for alkyl substituted cathinones. On the contrary, the use of the PDA detector is also conventional, and could aid in the differentiation of substitution patterns on aromatic rings and particular aromatic frame skeletons. The classic examples are naturally occurring polyphenols containing flavonoid skeletons, the substitution patterns of which have been elucidated based on the patterns of wavelengths of maximum absorption $\left(\lambda_{\max }\right)$ in the UV spectra. ${ }^{19,20}$

This article reports our attempts to differentiate $N$-alkylated cathinones and regioisomers based on their alkylated aromatic rings using a combination of product ion spectrometry by GCEI-MS-MS and UV spectra obtained by LC-PDA analysis. This procedure was successfully applied to a series of $\mathrm{N}$-alkylated cathinones with alkyl substituent(s) on the aromatic ring.

\section{Experimental}

\section{Reagents and chemicals}

Authentic synthetic cathinones as hydrochlorides, 2-ethylmethcathinone (1), 3-ethylmethcathinone (2), 4-ethylmethcathinone (3), 2,3-dimethylmethcathinone (4), 2,4-dimethylmethcathinone (5), 3,4-dimethylmethcathinone (6), 4-methylbuphedrone (7), 4-methylethcathinone (8), $\mathrm{N}, \mathrm{N}$ dimethylcathinone (9), pentedrone (10), N-ethylbuphedrone (11), 4-methyl- $N$-methylbuphedrone (12), $N$-ethylmethcathinone (13), $\alpha$-ethylaminopentiophenone (14), and $\alpha$-dimethylaminopentiophenone (15), were purchased from Cayman Chemical Co. (Ann Arbor, MI USA). Standard stock solutions of these compounds were prepared at $1 \mathrm{mg} / \mathrm{mL}$ (in methanol) and stored at $-20^{\circ} \mathrm{C}$ until analysis. These solutions were diluted in methanol to $10 \mu \mathrm{g} / \mathrm{mL}$ working solutions prior to instrumental analysis. All other common chemicals and solvents were of analytical reagent grade or LC-MS grade. The unknown herbaltype product containing mixed dried plants was purchased from a shop in Gifu, Japan, in July 2012.

\section{Preparation of sample solution}

The herbal-type product $(30 \mathrm{mg}$ ) was crushed to a powder and extracted with $3 \mathrm{~mL}$ of methanol under ultrasonication for $10 \mathrm{~min}$. After centrifugation (5 min, $3000 \mathrm{rpm}$ ), the supernatant solution was passed through a membrane filter (Millex-LH $0.45 \mu \mathrm{m}$ filter unit; Merck Millipore, Germany). Moreover, if necessary, the solution was diluted with methanol to a suitable concentration before instrumental analysis.

\section{Analytical methods}

GC-MS analysis was performed using a TRACE 1310GC and ISQ LT (Thermo Fisher Scientific, MA, USA). Samples were separated with a DB-5MS capillary column $(30 \mathrm{~m} \times 0.25 \mathrm{~mm}$ i.d.; $0.25 \mu \mathrm{m}$ film thickness; Agilent Technologies, Santa Clara, CA, USA) with helium as the carrier gas at a constant flow rate of $1.1 \mathrm{~mL} / \mathrm{min}$. The oven temperature was programmed as follows: held at $80^{\circ} \mathrm{C}$ for $1 \mathrm{~min}$; ramp linearly at $10^{\circ} \mathrm{C} / \mathrm{min}$ to $300^{\circ} \mathrm{C}$; and held at $300^{\circ} \mathrm{C}$ for $10 \mathrm{~min}$. The injector temperature was set at $250^{\circ} \mathrm{C}$, and the injection volume was $1 \mu \mathrm{L}$ (splitless mode). The GC interface and ion-source temperature were maintained at 280 and $250^{\circ} \mathrm{C}$, respectively. Ionization was performed in the electron ionization mode at $70 \mathrm{eV}$. A mass spectral library search was conducted using the Searchable Mass Spectral Library Ver. 2.2 downloaded from the SWGDRUG home page. ${ }^{21}$

GC-MS-MS was performed using an Agilent 7890A/7000 GC-MS Triple Quad triple quadrupole mass spectrometer equipped with an Agilent 7693 autosampler (Agilent Technologies). The instrument was controlled using an Agilent Mass Hunter Acquisition module (Ver. B.04.00). Samples were introduced via a DB-5MS+DG capillary column $(30 \mathrm{~m} \times$ $0.25 \mathrm{~mm}$ i.d.; $0.25 \mu \mathrm{m}$ film thickness with $10 \mathrm{~m}$ DuraGuard; Agilent Technologies). The analytical conditions were the same as those in GC-MS analysis, except for the following conditions: collision gas, $\mathrm{N}_{2}(1.5 \mathrm{~mL} / \mathrm{min})$; product ion scan mode using $m / z 72,86,100$, and 133 as precursor ions. Product ion spectra were obtained by varying the collision energy (CE) from 5 to $35 \mathrm{~V}$ in units of $10 \mathrm{~V}$. LC-PDA analysis was performed on an Agilent Technologies liquid chromatograph (1100 series) composed of a quaternary pump (G1311A), a thermostat (G1330A), a column compartment (G1316A), and an autosampler (G1329A) coupled to a PDA detector. The instrument was controlled by an Agilent ChemStation (Ver. A.06.04J). Chromatographic separation was carried out on an Atlantis T3 column (4.6 i.d. $\times 150 \mathrm{~mm}$; particle size, $5.0 \mu \mathrm{m}$; Waters, MA, USA). The mobile phase comprised (A) $0.1 \%$ formic acid in water and (B) $0.1 \%$ formic acid in acetonitrile. The column was kept at $40^{\circ} \mathrm{C}$, and the gradient program was as follows: linear gradient of B from 5 to $20 \%$ from 0 to $20 \mathrm{~min}$; linear gradient of B from 20 to $95 \%$ from 20 to $35 \mathrm{~min}$; and isocratic elution of $95 \% \mathrm{~B}$ from 35 to $40 \mathrm{~min}$. The flow rate and the injection volume were $1.0 \mathrm{~mL} / \mathrm{min}$ and $10 \mu \mathrm{L}$, respectively.

LC-MS analysis was performed on an Agilent 1100 Series LC/MSD equipped electron ion spray and an Atlantis T3 column (2.1 i.d. $\times 150 \mathrm{~mm}$; particle size, $5.0 \mu \mathrm{m}$; Waters). The mobile phase and the column temperature were the same as those in LC-PDA. The flow rate and the injection volume were 0.2 $\mathrm{mL} / \mathrm{min}$ and $2 \mu \mathrm{L}$, respectively.

\section{Results and Discussion}

\section{EI-mass spectra of synthetic cathinones}

Table 1 gives the structures of the synthetic cathinones examined in this study $(\mathbf{1}-\mathbf{1 5})$, which are tabulated by the amino group substituents $\left(\mathrm{R}_{1 \mathrm{a}}\right.$ and $\left.\mathrm{R}_{1 \mathrm{~b}}\right)$, propanone termini $\left(\mathrm{R}_{2}\right)$, and phenyl rings $\left(R_{3}\right.$ and $\left.R_{4}\right)$. The fragment ions observed in the EI-mass spectra, iminium ion as the base peak, and acylium ion are also presented in Table 1 . As previously reported, ${ }^{7,10,11,13}$ the main fragmentation occurs by dissociation of the $\mathrm{C}-\mathrm{C}$ bond between the $\alpha$ and $\beta$ carbon atoms under EI conditions. A key feature of the mass spectral fragmentation of cathinones is the $\alpha$-cleavage process, which results in the formation of the iminium ion (Fig. S1, Supporting Information). Domination of the iminium ion in the EI-mass spectrum is also acceptable owing to preferable dissociation of the $\mathrm{C}_{\alpha}-\mathrm{C}_{\beta}$ bond, whereas the peak for the molecular ion is hardly observed, and the other fragment peaks are small. The synthetic cathinones substituted with either $\mathrm{H}, \mathrm{CH}_{3}$, or $\mathrm{C}_{2} \mathrm{H}_{5}$ at the $\mathrm{R}_{1 \mathrm{a}}$ and $\mathrm{R}_{1 \mathrm{~b}}$ positions, and $n$-alkyl containing $\mathrm{C}_{1}-\mathrm{C}_{7}$ at the position of $\mathrm{R}_{2}$ are scheduled drugs in Japan. Iminium ions formed from these cathinones are represented by $\mathrm{C}_{\mathrm{n}} \mathrm{H}_{2 \mathrm{n}+2} \mathrm{~N}^{+}$, resulting in a base peak of $m / z 44,58$, $72,86,100,114$, and 128, depending on the number of carbon atoms contained in the iminium ion. Four types of iminium ions $\mathrm{C}_{5} \mathrm{H}_{12} \mathrm{~N}^{+}(\mathbf{1 0 a}-13 a)$ with $m / z, 86$ are shown in Fig. 1, which are formed from pentedrone (10), $N$-ethylbuphedrone (11), 4-methyl- $N$-dimethylbuphedrone (12), and $N$-ethylmethcathinone 
Table 1 Structures of cathinone derivatives tabulated with their base peaks upon electron ionization

\begin{tabular}{|c|c|c|c|c|c|c|c|}
\hline Compound & $\mathrm{R}_{\mathrm{la}}$ & $\mathrm{R}_{1 \mathrm{~b}}$ & $\begin{array}{l}\mathrm{R}_{2} \\
\mathrm{R}_{2}\end{array}$ & $\mathrm{R}_{3}$ & $\mathrm{R}_{4}$ & $\begin{array}{c}\text { Iminium ion } \\
\text { (Base peak) }[\mathrm{m} / \mathrm{z}]\end{array}$ & $\begin{array}{l}\text { Acylium ion } \\
{[\mathrm{m} / \mathrm{z}]}\end{array}$ \\
\hline 2-Ethylmethcathinone $(\mathbf{1})^{\mathrm{a}}$ & $\mathrm{H}$ & $\mathrm{CH}_{3}$ & $\mathrm{H}$ & $\mathrm{C}_{2} \mathrm{H}_{5}$ & $\mathrm{H}$ & \multirow{6}{*}{58} & \multirow{6}{*}{133} \\
\hline 3-Ethylmethcathinone $(2)^{\mathrm{a}}$ & $\mathrm{H}$ & $\mathrm{CH}_{3}$ & $\mathrm{H}$ & $\mathrm{C}_{2} \mathrm{H}_{5}$ & $\mathrm{H}$ & & \\
\hline 4-Ethylmethcathinone $(\mathbf{3})^{\mathrm{a}}$ & $\mathrm{H}$ & $\mathrm{CH}_{3}$ & $\mathrm{H}$ & $\mathrm{C}_{2} \mathrm{H}_{5}$ & $\mathrm{H}$ & & \\
\hline 2,3-Dimethylmethcathinone (4) & $\mathrm{H}$ & $\mathrm{CH}_{3}$ & $\mathrm{H}$ & $\mathrm{CH}_{3}$ & $\mathrm{CH}_{3}$ & & \\
\hline 2,4-Dimethylmethcathinone (5) & $\mathrm{H}$ & $\mathrm{CH}_{3}$ & $\mathrm{H}$ & $\mathrm{CH}_{3}$ & $\mathrm{CH}_{3}$ & & \\
\hline 3,4-Dimethylmethcathinone $(\mathbf{6})^{\mathrm{a}}$ & $\mathrm{H}$ & $\mathrm{CH}_{3}$ & $\mathrm{H}$ & $\mathrm{CH}_{3}$ & $\mathrm{CH}_{3}$ & & \\
\hline 4-Methylbuphedrone (7) ${ }^{\mathrm{a}}$ & $\mathrm{H}$ & $\mathrm{CH}_{3}$ & $\mathrm{CH}_{3}$ & $\mathrm{CH}_{3}$ & $\mathrm{H}$ & \multirow{3}{*}{72} & 119 \\
\hline 4-Methylethcathinone $(\mathbf{8})^{\mathrm{a}}$ & $\mathrm{H}$ & $\mathrm{C}_{2} \mathrm{H}_{5}$ & $\mathrm{H}$ & $\mathrm{CH}_{3}$ & $\mathrm{H}$ & & 119 \\
\hline$N, N$-Dimethylcathinone (9) & $\mathrm{CH}_{3}$ & $\mathrm{CH}_{3}$ & $\mathrm{H}$ & $\mathrm{H}$ & $\mathrm{H}$ & & 105 \\
\hline Pentedrone $(\mathbf{1 0})^{\mathrm{a}}$ & $\mathrm{H}$ & $\mathrm{CH}_{3}$ & $\mathrm{C}_{2} \mathrm{H}_{5}$ & $\mathrm{H}$ & $\mathrm{H}$ & \multirow{4}{*}{86} & 105 \\
\hline$N$-Ethylbuphedrone $(\mathbf{1 1})^{\mathrm{a}}$ & $\mathrm{H}$ & $\mathrm{C}_{2} \mathrm{H}_{5}$ & $\mathrm{CH}_{3}$ & $\mathrm{H}$ & $\mathrm{H}$ & & 105 \\
\hline 4-Methyl- $N$-dimethylbuphedrone $(\mathbf{1 2})^{\mathrm{a}}$ & $\mathrm{CH}_{3}$ & $\mathrm{CH}_{3}$ & $\mathrm{CH}_{3}$ & $\mathrm{CH}_{3}$ & $\mathrm{H}$ & & 119 \\
\hline$N$-Ethylmethcathinone $(\mathbf{1 3})^{\mathrm{a}}$ & $\mathrm{CH}_{3}$ & $\mathrm{C}_{2} \mathrm{H}_{5}$ & $\mathrm{H}$ & $\mathrm{H}$ & $\mathrm{H}$ & & 105 \\
\hline$\alpha$-Ethylaminopentiophenone $(\mathbf{1 4})^{\mathrm{a}}$ & $\mathrm{H}$ & $\mathrm{C}_{2} \mathrm{H}_{5}$ & $\mathrm{C}_{2} \mathrm{H}_{5}$ & $\mathrm{H}$ & $\mathrm{H}$ & \multirow[b]{2}{*}{100} & 105 \\
\hline$\alpha$-Dimethylaminopentiophenone $(\mathbf{1 5})^{\mathrm{a}}$ & $\mathrm{CH}_{3}$ & $\mathrm{CH}_{3}$ & $\mathrm{C}_{2} \mathrm{H}_{5}$ & $\mathrm{H}$ & $\mathrm{H}$ & & 105 \\
\hline
\end{tabular}

a. Scheduled drugs in Japan (Shitei-Yakubutsu).<smiles>CCCC=[NH+]C</smiles>

$10 a$

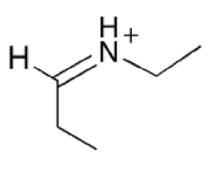

$11 \mathrm{a}$<smiles>CCC=[N+](C)C</smiles>

$12 a$

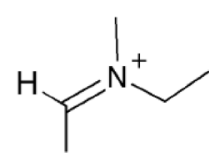

$13 a$

Fig. 1 Dominant iminium ions (10a- 13a) observed in the EI-mass spectra of synthetic cathinones $\mathbf{1 0}$ - 13 .

(13). Iminium ions 10a-13a are the same in composition but differ in structure. The base peak mass of cathinone is useful for estimating the number of carbon atoms present in the iminium ion, contributing to obtaining partial information on the cathinone. However, the secondary and tertiary fragmentations of the iminium ion are required for the differentiation and identification of the chemical structures.

The formation of the acylium ion is another typical reaction observed in cathinones under EI conditions. This reaction involves dissociation of the $\mathrm{C}_{\alpha}-\mathrm{C}_{\beta}$ bond and elimination of the alkyl group at the same location as for the formation of the iminium ion. A subsequent loss of carbon monoxide from an acylium ion results in the phenyl cation, as indicated in Fig. S1 (Supporting Information). The phenyl cation $(\mathrm{m} / \mathrm{z} \quad 77)$, methylphenyl cation $(\mathrm{m} / \mathrm{z}, 91)$, and dimethylphenyl cation $(\mathrm{m} / \mathrm{z}$ 105) are typical examples of fragment ions produced by the subsequent loss of the corresponding acylium ions at $\mathrm{m} / \mathrm{z} 105$, 119, and 133 (Table 1). These mass spectroscopic patterns are useful for interpreting the elemental composition, but do not differentiate between regioisomers with different substitution patterns on the aromatic ring. Thus, an alternative approach for the differentiation of such regioisomers $(\mathbf{1}-\mathbf{3}$ and $\mathbf{4 - 6})$ is required.

Structurally isomeric differentiation of iminium ion by GC-EI$M S-M S$

On the basis of fragmentation information under the EI conditions, the iminium ions were selected as precursor ions for the differentiation of structural isomers by GC-MS-MS. The product ion spectra from the iminium ions (10a-13a) of cathinones $\mathbf{1 0}-\mathbf{1 3}$ at CEs of 5, 15, 25, and $35 \mathrm{~V}$ are shown in Fig. 2. The product ions at $m / z, 58,56,44,42$, and 41 in addition to the precursor ions at $\mathrm{m} / \mathrm{z}, 86$ were commonly observed for 10a - 13a, while ions were observed at $\mathrm{m} / \mathrm{z}, 71$ for 13a and $\mathrm{m} / \mathrm{z}$ 57 for 10a and 12a. All of the fragments from 10a-13a showed different relative intensities under different $\mathrm{CE}$ conditions. The spectral profiles of the regioisomeric iminium ions showed that the relative intensities of the product ions varied at constant $\mathrm{CE}$. These results suggested that the iminium ion could be discriminated using GC-MS-MS based on the relative-intensity difference of the product ions at a particular CE. Previous reports have also shown that the product ion spectra of the iminium ions yield structural information for their identification. ${ }^{22,23}$ This result led us to investigate the optimal $\mathrm{CE}$ for isomeric differentiation with reproducible mass spectra.

Although more fragment ions could be obtained at CEs of 25 and $35 \mathrm{~V}$ to achieve accurate discrimination, some key fragment ions disappeared or appeared with diminished intensity under these conditions, as demonstrated by the product ions at $\mathrm{m} / \mathrm{z}, 58$ for $\mathbf{1 1}$ and $\mathrm{m} / \mathrm{z}, 71$ for $\mathbf{1 2}$. At low CE (5 V), the spectra were simpler, and showed a low relative intensity for key fragments due to the low dissociation of iminium ions and essentially lack in information. Thus, we selected $15 \mathrm{~V}$ as the $\mathrm{CE}$ for differentiation of the four iminium ions, and the reproducibility of the observed product ions was investigated at this CE. The coefficient of variation $(\% \mathrm{CV})$ of the relative intensity of the major product ions was less than $7.3 \%$ (Table 2), confirming the good reproducibility of the product ion spectra.

A comparison of the product ions dissociated at a CE of $15 \mathrm{~V}$ indicated that the four iminium ions 10a-13a were very 
1) Pentedrone (10)
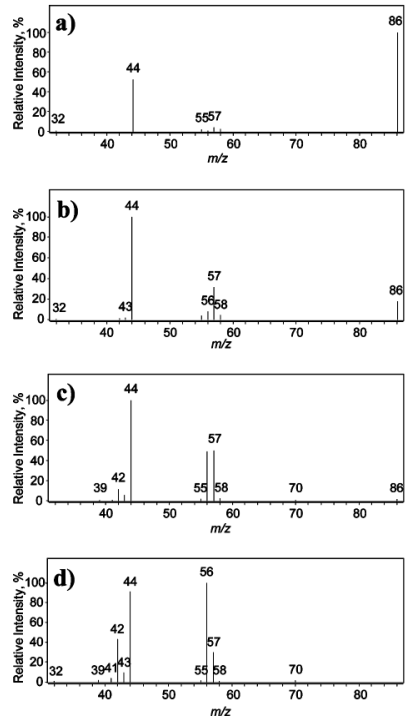

2) $N$-Ethylbuphedrone (11)
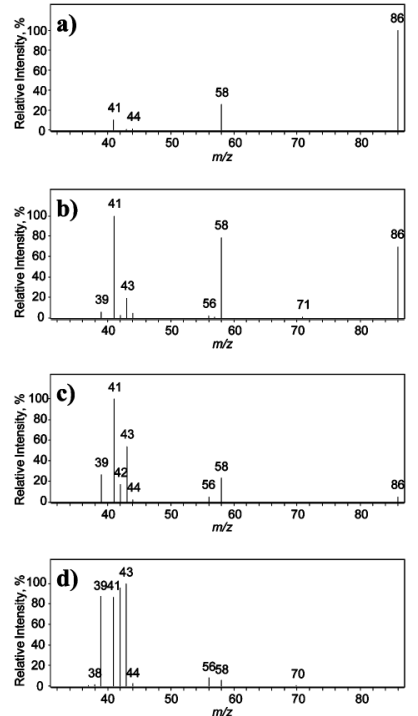

3) 4-Methyl- $N$-methylbuphedrone (12)
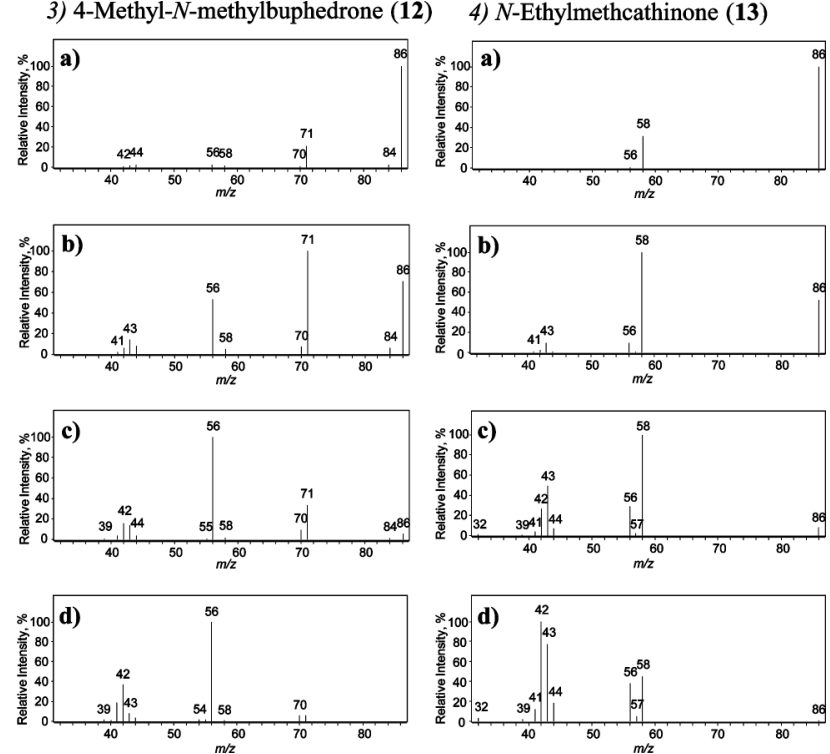

Fig. 2 Product ion spectra obtained from the precursor ions at $m / z, 86(\mathbf{1 0 a}-\mathbf{1 3 a})$ for 1 , pentedrone (10); 2, $N$-ethylbuphedrone (11); 3, 4-methyl- $N$-methylbuphedrone (12); 4, $N$-ethylmethcathinone (13).

Collision energy was set at a) 5 , b) 15 , c) 25 , and d) $35 \mathrm{~V}$.

Table 2 Coefficient of variation $(\% \mathrm{CV})$ of relative intensity of the main ion observed in the product ion spectra obtained by dissociation at $\mathrm{CE}=15 \mathrm{~V}$ from the precursor ion at $m / z, 86(n=5)$

\begin{tabular}{|c|c|c|c|c|c|c|c|c|c|c|c|c|}
\hline \multirow{2}{*}{ Compound } & \multicolumn{12}{|c|}{$m / z$} \\
\hline & 39 & 41 & 42 & 43 & 44 & 56 & 57 & 58 & 70 & 71 & 84 & 86 \\
\hline Pentedrone (10) & - & - & - & - & a & $\begin{array}{c}4.0 \\
(8.2)\end{array}$ & $\begin{array}{c}2.1 \\
(33.0)\end{array}$ & - & - & - & - & $\begin{array}{c}3.8 \\
(19.0)\end{array}$ \\
\hline$N$-Ethylbuphedrone (11) & $\begin{array}{c}3.6 \\
(5.7)\end{array}$ & a & - & $\begin{array}{c}1.8 \\
(19.6)\end{array}$ & - & - & - & $\begin{array}{c}2.9 \\
(79.5)\end{array}$ & - & - & - & $\begin{array}{c}7.3 \\
(71.4)\end{array}$ \\
\hline 4-Methyl- $N$-dimethylbuphedrone (12) & - & - & $\begin{array}{c}4.4 \\
(6.0)\end{array}$ & $\begin{array}{c}3.8 \\
(13.7)\end{array}$ & $\begin{array}{c}4.7 \\
(7.4)\end{array}$ & $\begin{array}{c}2.2 \\
(51.9)\end{array}$ & - & - & $\begin{array}{c}3.5 \\
(7.2)\end{array}$ & $\mathrm{a}$ & $\begin{array}{c}5.7 \\
(6.2)\end{array}$ & $\begin{array}{c}1.7 \\
(72.6)\end{array}$ \\
\hline$N$-Ethylmethcathinone (13) & - & - & - & $\begin{array}{r}4.7 \\
(9.3)\end{array}$ & - & $\begin{array}{c}3.6 \\
(9.7)\end{array}$ & - & $\mathrm{a}$ & - & - & - & $\begin{array}{c}1.8 \\
(54.6)\end{array}$ \\
\hline
\end{tabular}

—, Not observed. a. Base peak. Relative intensity is shown in the parentheses.

distinguishable from each other based on the differences in their detected ions and fragmentation patterns. The key fragment ions $(\mathrm{m} / \mathrm{z}$ (rel. int.)) were $57(33.0)$ and $44(100.0)$ for $\mathbf{1 0}, 58$ (79.5) and 41 (100) for 11, 71 (100) and 56 (51.9) for 12, and 58 (100) for 13 (Fig. 2), which are explained by the plausible reaction pathways, as follows (Figs. $3 \mathrm{a}-3 \mathrm{~d}$ ). The scheme can be reasonably explained by three core mechanisms: the elimination of radical species (A) or neutral molecule (B); dehydrogenation; and C-C bond formation $(\mathbf{C})$. Ethylene $\left(\mathrm{C}_{2} \mathrm{H}_{4}\right.$ : M28) is a neutral substance eliminated in the case of iminium ions from 11 and $\mathbf{1 3}$ at $\mathrm{m} / z, 86\left(\mathrm{C}_{5} \mathrm{H}_{12} \mathrm{~N}^{+}\right)$, which leads to the formation of other iminium ion observable at $\mathrm{m} / z .58\left(\mathrm{C}_{3} \mathrm{H}_{8} \mathrm{~N}^{+}\right)$ with high intensity (Figs. $3 \mathrm{~b}$ and $3 \mathrm{~d}$ ). On the other hand, the iminium ions derived from 10, which contain an $N$-methylamine moiety, are not favorable for the elimination of an $N$-alkyl group as a methyl radical is strongly prohibited, resulting in the loss of the other neutral species of propene to produce the ion at $\mathrm{m} / \mathrm{z} 44$ $\left(\mathrm{C}_{2} \mathrm{H}_{6} \mathrm{~N}^{+}\right)$(Fig. 3a). The $\left[\mathrm{M}_{\text {iminium ion }}-29\right]^{+}$fragment ion at $\mathrm{m} / \mathrm{z}, 57$ is assumed to be a butyl cation $\left(\mathrm{C}_{4} \mathrm{H}_{9}{ }^{+}\right)$after the loss of the other neutral species $-\mathrm{CH}_{3} \mathrm{~N}$, which resulted from carbocation formation, followed by $\mathrm{C}-\mathrm{N}$ bond cleavage. This phenomenon has been observed for 11. The other key fragment ion at $m / z, 41$ $\left(\mathrm{C}_{3} \mathrm{H}_{5}{ }^{+}\right)$for $\mathbf{1 1}$ is well explained as follows: the iminium ion 11a follows the same pattern via elimination of the neutral species $\left(\mathrm{C}_{2} \mathrm{H}_{5} \mathrm{~N}\right.$ : M43), followed by removal of two hydrogen atoms from a propyl cation at $\mathrm{m} / z 43\left(\mathrm{C}_{3} \mathrm{H}_{7}{ }^{+}\right)$(Fig. 3b). In addition, a characteristic ion at $\mathrm{m} / \mathrm{z}, 39$ for the cyclopropenyl cation $\left(\mathrm{C}_{3} \mathrm{H}_{3}{ }^{+}\right)$ was observed as a fragment of 11a, allowing for discrimination of the ethyl group at the $\mathrm{R}_{2}$ position, especially concerning spectra obtained in the conditions of higher CEs (Fig. 2). We have confirmed the same phenomenon for 12, where the $\left[\mathrm{M}_{\text {iminium ion }}-43\right]^{+}$ion was present with the cyclopropenyl cation as minority fragments at higher values of CE (Fig. 2). The significant fragment ions for 12 at $\mathrm{m} / \mathrm{z}, 71$ and 56 can be concisely explained as follows (Fig. 3c). Although elimination of the methyl radical is prohibited, the presence of the other $\mathrm{N}$-methyl group can stabilize the newly generated iminium ion radical $\left.\left(m / z, 71, \mathrm{C}_{4} \mathrm{H}_{9} \mathrm{~N}^{*+}\right)\right)$, with the highest ion intensity in the spectrum at a $\mathrm{CE}$ of $15 \mathrm{~V}$. The other fragment at $\mathrm{m} / \mathrm{z} 56$ $\left(\mathrm{C}_{3} \mathrm{H}_{6} \mathrm{~N}^{+}\right)$is assumed to be generated from the key intermediate at $\mathrm{m} / z .58\left(\mathrm{C}_{3} \mathrm{H}_{8} \mathrm{~N}^{+}\right)$, which was produced by the elimination of ethylene $\left(\mathrm{C}_{2} \mathrm{H}_{4}\right.$ : M28) from the precursor iminium ion (Fig. $\left.3 \mathrm{~d}\right)$. 
a)

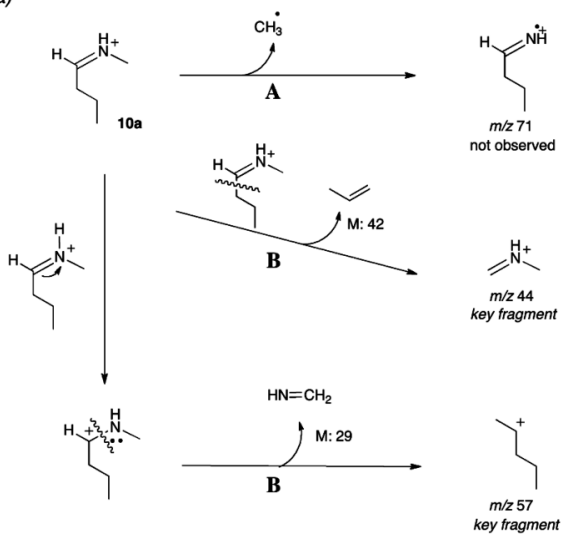

b)

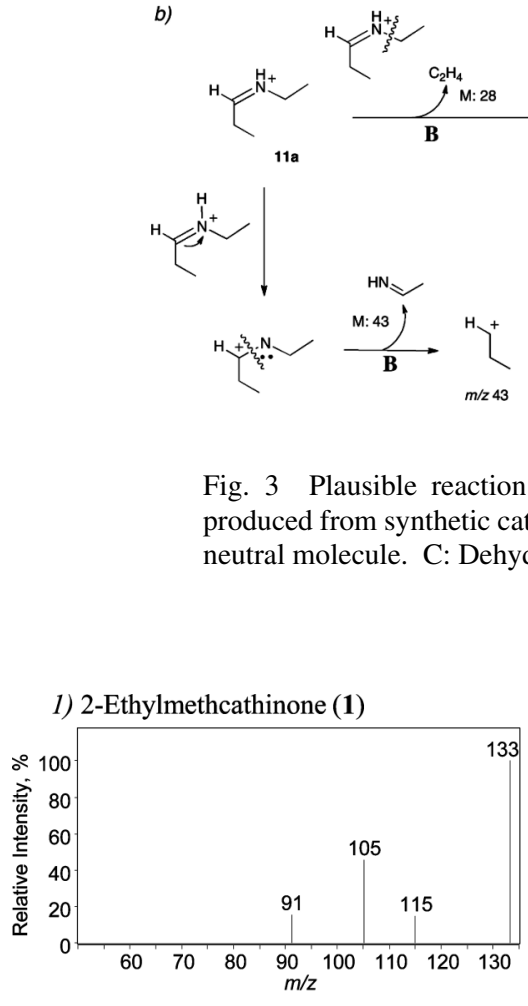

1) 2-Ethylmethcathinone (1)

4) 2,3-Dimethylmethcathinone (4)

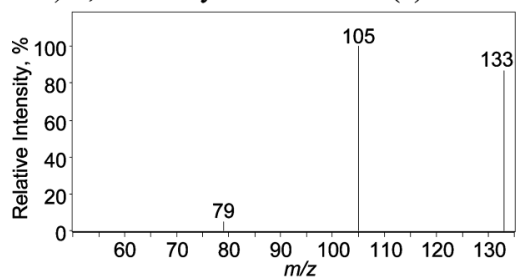

2) 3-Ethylmethcathinone (2)

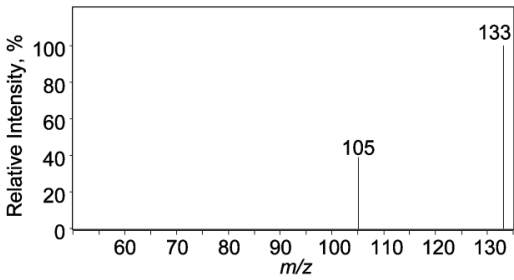

5) 2,4-Dimethylmethcathinone (5)

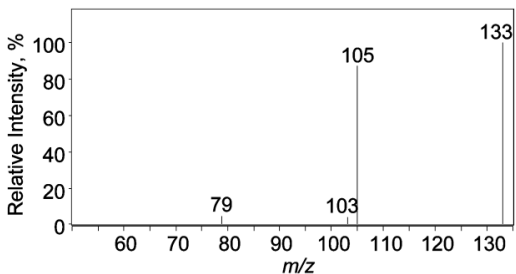

c)
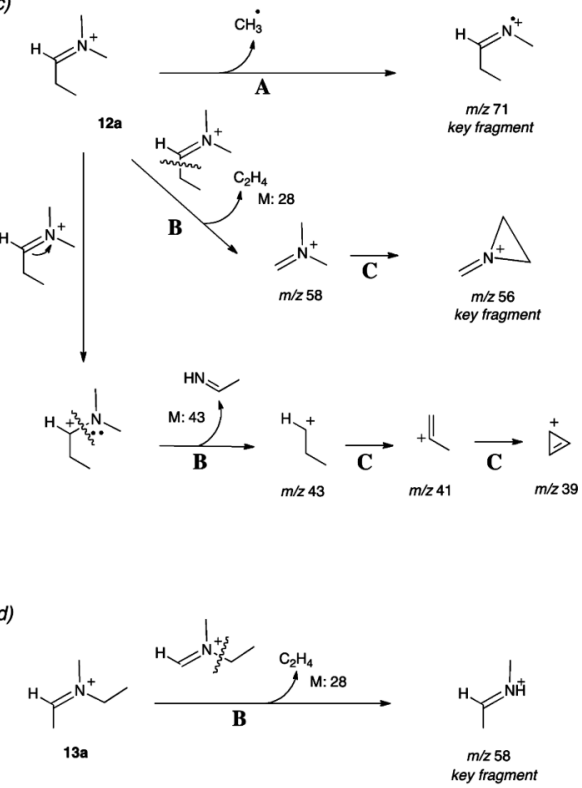

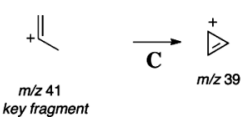

Fig. 4 Product ion spectra obtained from the precursor ions at $\mathrm{m} / \mathrm{z} 133$ for 1, 2-ethylmethcathinone (1); 2, 3-ethylmethcathinone (2); 3, 4-ethylmethcathinone (3); 4, 2,3-dimethylmethcathinone (4); 5, 2,4-dimethylmethcathinone (5); 6, 3,4-dimethylmethcathinone (6). Collision energy was set at 5 V.

We further conducted GC-EI-MS-MS experiments to differentiate isomeric iminium ions of $\mathrm{m} / \mathrm{z}, 72$ and 100, which correspond to $\mathrm{C}_{4} \mathrm{H}_{10} \mathrm{~N}^{+}$and $\mathrm{C}_{6} \mathrm{H}_{14} \mathrm{~N}^{+}$, respectively. The precursor ions at $\mathrm{m} / \mathrm{z} 72$ from 4-methylbuphedrone (7), 4-methylethcathinone (8), and $N, N$-dimethylcathinone (9), as well as those at $\mathrm{m} / \mathrm{z}, 100$ from $\alpha$-ethylaminopentiophenone (14) and $\alpha$-dimethylaminopentiophenone (15), were further dissociated under the same conditions as for 10-13 (CE of $15 \mathrm{~V})$. The results for $\mathbf{7}-\mathbf{9}, \mathbf{1 4}$, and $\mathbf{1 5}$ showed clear differences and key fragments (i.e., $\mathrm{m} / \mathrm{z}$ 57, 44, and 42 for $7-9$ and $\mathrm{m} / \mathrm{z} 71$, 58 , and 56 for $\mathbf{1 4}$ and $\mathbf{1 5}$ ) due to the structural and regioisomerism of the substituents on $\mathrm{R}_{1 \mathrm{a}}, \mathrm{R}_{1 \mathrm{~b}}$, and $\mathrm{R}_{2}$, as also observed for $10-13$ (Fig. S2, Supporting Information). These results strongly support the applicability of the proposed GC-EI-MS-MS- 

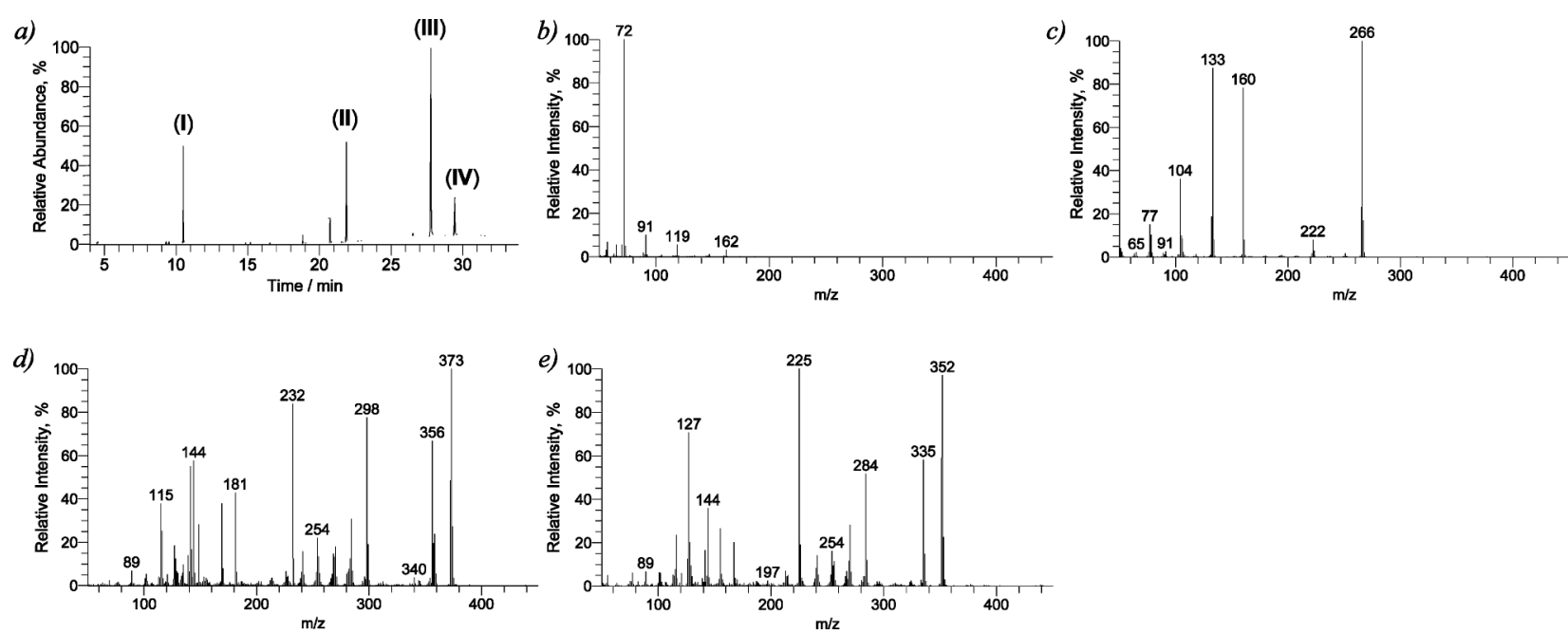

Fig. 5 GC-MS analysis of unknown sample. a) Total ion chromatogram. EI-mass spectra for the detected b) peak I, c) II, d) III, and e) IV.

assisted procedure for the structural differentiation of iminium ions derived from synthetic cathinones.

\section{Differentiation of aromatic structures by GC-EI-MS-MS and LC- PDA}

Acylium ion-focused structural isomeric differentiation was also investigated using the collision-induced dissociation (CID) of ions stemming from synthetic cathinones bearing positional isomerism on the aromatic moiety; the scheduled drugs include a number of such isomers, making their differentiation more difficult, and a concise procedure for their discrimination still needs to be developed. We employed a two-step approach using six synthetic cathinones, 2-ethylmethcathinone (1), 3-ethylmethcathinone (2), 4-ethylmethcathinone (3), 2,3-dimethylmethcathinone (4), 2,4-dimethylmethcathinone (5), and 3,4-dimethylmethcathinone $(\mathbf{6})$, which produce the same fragments due to the acylium ion. In addition to the precursor ions at $\mathrm{m} / \mathrm{z}$ 133, common product ions at $\mathrm{m} / \mathrm{z} 105$ $\left[\mathrm{M}_{\text {acylium ion }}-28\right]^{+}$were observed by CID at CE of $5 \mathrm{~V}$ for $\mathbf{1}-\mathbf{6}$ (Fig. 4). The spectral profiles of the product ions for the isomers with the same substituent(s) on the aromatic ring were similar regardless of positional isomerism [1-3 and 4-6], while the relative intensities of the product ions for structural isomers varied, as demonstrated by the approximate ratios of $\mathrm{m} / \mathrm{z} 133$ to 105 of 2:1 and 1:1 for $\mathbf{1}-\mathbf{3}$ and $\mathbf{4}-\mathbf{6}$, respectively. The results indicated that the structural isomers can be discriminated by GC-MS-MS based on the intensity difference of the product ions originating from the acylium ion. However, it was somewhat difficult to discriminate each isomer $(\mathbf{1}-\mathbf{3}$ and 4 - 6) from the other byproduct ion spectra at a CE of $5 \mathrm{~V}$. We next moved on to UV-aided differentiation using LC-PDA. A difference in $\lambda_{\max }$ corresponding to aromatic rings was clearly observed for ethylmethcathinones ( $\lambda_{\max }: 1,251 \mathrm{~nm} ; 2,255 \mathrm{~nm}$; 3, $264 \mathrm{~nm})$ and dimethylmethcathinones $\left(\lambda_{\max }: 4,254 \mathrm{~nm} ; \mathbf{5}\right.$, $263 \mathrm{~nm} ; \mathbf{6}, 267 \mathrm{~nm}$ ), suggesting the possibility of differentiating these compounds based on their UV spectra (Fig. S3, Supporting Information). The combination of acylium ion-focused GC-EIMS-MS and LC-PDA experiments enabled complete differentiation of 1-6, and could potentially be used to discriminate the growing number of isomeric cathinones based on their aromatic rings.
Analysis of unknown sample

An unknown herbal-type product was analyzed for screening by GC-MS and LC-MS. Four strong peaks I - IV were observed in the total ion chromatogram (TIC) in GC-MS analysis (Fig. 5a). The EI-mass spectrum of $\mathbf{I}$ exhibited a simple pattern with a base peak at $m / z 72$ accompanied by a weak fragment peak at $m / z 119$ (Fig. 5b), while II - IV showed several intense peaks due to fragment ions (Figs. 5c-5e). The TIC from LC-MS also showed four peaks $\mathbf{V}$ - VIII with retention times of $14.7,37.2,38.9$, and $43.1 \mathrm{~min}$, due to the protonated quasimolecular ions at $m / z 192,353,267$, and 374, respectively (data not shown). These results suggest that peaks V - VIII on LC correspond to peaks I, IV, III, and II on GC bearing molecular ions at $\mathrm{m} / \mathrm{z} 191,352,266$, and 373, respectively. Peak I was presumed to be a cathinone derivative of molecular weight 191 generating iminium ion $\left(\mathrm{m} / \mathrm{z}, 72, \mathrm{C}_{4} \mathrm{H}_{10} \mathrm{~N}^{+}\right)$and acylium ion $\left(\mathrm{m} / \mathrm{z}, 119, \mathrm{CH}_{3} \mathrm{C}_{6} \mathrm{H}_{4} \mathrm{CO}^{+}\right)$. However, cathinone derivatives showing this profiles are included in at least 12 candidates for scheduled drugs in Japan (e.g., 4-methylethcathinone, 3-methylbuphedrone, 4-methyl- $\mathrm{N}, \mathrm{N}$ dimethylcathinone, 2-methyl- $\alpha$-aminopentiophenone, etc.).

A product ion scan of $\mathrm{m} / \mathrm{z}, 72$ was performed using GC-MSMS to aid in the above structural determination. The resulting product ion spectrum at $\mathrm{CE}$ of $15 \mathrm{~V}$ was identical to that of a cathinone derivative having $\mathrm{R}_{1 \mathrm{a}}=\mathrm{H}, \quad \mathrm{R}_{1 \mathrm{~b}}=\mathrm{CH}_{3}, \mathrm{R}_{2}=\mathrm{CH}_{3}$ (Fig. 6a and Fig. 2S, Supporting Information). In addition, the UV spectrum of peak $\mathbf{V}$ showed a $\lambda_{\max }$ at $264 \mathrm{~nm}$ (Fig. 6b), indicating the presence of a 4-methylphenyl group in the molecule. The assignment was verified by analytical data from an authentic 4-methylbuphedrone (7). By GC mass spectral library search and authentic standard analysis, peaks II, III, and IV were identified as URB-754, MAM-2201, and AM-2232, respectively.

Thus, GC-MS-MS and LC-PDA analyses are very helpful for the structural characterization of unknown cathinone derivatives in illicit drug products, reducing the shortcomings of GC-MS and LC-MS analyses. Although LC-PDA generally has a low detection sensitivity compared to mass spectrometry, it is sufficiently capable of the detection and characterization of compounds in illicit drug products on the condition that each peak is successfully separated because the concentrations of these compounds in distributed products generally range from several to $100 \mathrm{mg} / \mathrm{g}$, in our experience. 

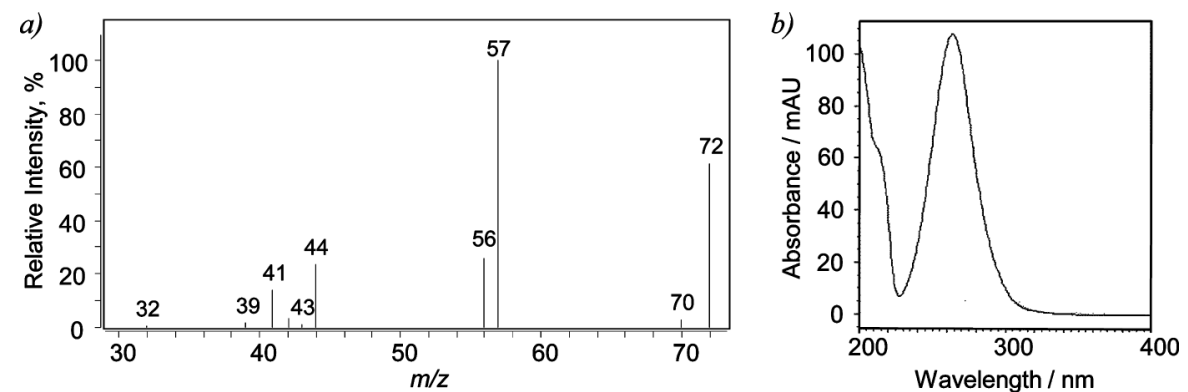

Fig. 6 GC-MS-MS and LC-PDA analyses of unknown sample. a) Product ion spectrum (CE $=15 \mathrm{~V})$ of $m / z, 72$ as precursor ion for the peak corresponding to peak $\mathbf{I}$ detected in GC-MS analysis. b) UV spectrum for the peak corresponding to peak $\mathbf{V}$ in LC-MS analysis.

\section{Conclusions}

The similar structures of cathinones are the main problem in their differentiation., ${ }^{7,810-14}$ The limited number of available reference materials is also a bottleneck when considering the growing number of similar derivatives. The vast variability in new psychoactive substances and similarities in their chemical structures suggest that using multiple analytical procedures for their specific identification is essential. GC-EI-MS is a primary screening tool. The iminium and acylium ions formed, which follow secondary and tertiary fragmentations detailed analyzed by GC-EI-MS-MS, are characteristic of cathinones and reflect their chemical structures. This article demonstrates that various cathinones and forthcoming novel illicit drugs can be differentiated based on a detailed analysis of product ion spectra from the iminium and acylium ions combined with an LC-PDA analysis. This procedure is very effective for reducing the number of likely candidate compounds, especially with limited availability of authentic standards. As such, this procedure may serve as a powerful approach in the isomeric identification of drugs in samples of unknown mixture.

\section{Acknowledgements}

This work was funded by the domestic grant for the regional society in Gifu Prefectural Institute for Health and Environmental Sciences. The study was supported by the Health and Labour Sciences Research Grants 2015 to K. K. (Research on Regulatory Science of Pharmaceuticals and Medical Devices, \#27170401).

\section{Supporting Information}

General mass-spectral-fragmentation pattern of cathinone derivatives under EI conditions are summarized in Fig. S1. Product ion spectra $(\mathrm{CE}=15 \mathrm{~V})$ obtained from the precursor ions at $\mathrm{m} / \mathrm{z}, 72$ for $\mathbf{7}-\mathbf{9}$ and $\mathrm{m} / \mathrm{z}, 100$ for $\mathbf{1 4}$ and $\mathbf{1 5}$ are shown in Fig. S2. UV spectra for cathinones ( 1 - 6) obtained by LC-PDA are shown in Fig. S3. These materials are available free of charge on the Web at http://www.jsac.or.jp/analsci/.

\section{References}

1. E. Underwood, Science, 2015, 347, 469.

2. B. O. Crews and M. S. Petrie, Clin. Chem., 2015, 61, 1000.

3. E. Underwood, Science, 2015, 347, 473.

4. M. Sparago, J. Wlos, J. Yuan, G. Hatzidimitriou, J. Tolliver, T. A. Dal Cason, J. Katz, and G. Ricaurte, J. Pharmacol. Exp. Ther., 1996, 279, 1043.

5. R. P. Archer, Forensic Sci. Int., 2009, 185, 10.

6. J. M. Prosser and L. S. Nelson, J. Med. Toxicol., 2012, 8, 33.

7. V. Lopez-Avila, W. Gao, and R. Urdahl, J. Pharm. Sci. Innov., 2012, 1, 44.

8. E. Fornal, Drug Test Anal., 2014, 6, 705.

9. A. Namera, M. Kawamura, A. Nakamoto, T. Saito, and M. Magao, Forensic Toxicol., 2015, 33, 175.

10. F. Westphal, P. Roesner, and T. Junge, Forensic Sci. Int., 2010, 194, 53.

11. F. Westphal and T. Junge, Forensic Sci. Int., 2012, 223, 97.

12. S. Matsuta, M. Katagi, H. Nishioka, H. Kamata, K. Sakaki, N. Shima, T. Kamata, A. Miki, M. Tatsuno, K. Zaitsu, K. Tsuboi, H. Tsuchihashi, and K. Suzuki, Jpn. J. Forensic Sci. Technol., 2014, 19, 77.

13. D. Zuba, Trends Anal. Chem., 2012, 32, 15.

14. E. Fornal, J. Pharm. Biomed. Anal., 2013, 81-82, 13.

15. E. Fornal, A. Stachniuk, and A. Wojtyla, J. Pharm. Biomed. Anal., 2013, 72, 139.

16. S. Armenta, S. Garrigues, M. de la Guardia, J. Brassier, M. Alcala, M. Blanco, C. Perez-Alfonso, and N. Galipienso, Drug Test Anal., 2015, 7, 280.

17. M. Joshi, B. Cetroni, A. Camacho, C. Krueger, and A. J. Midey, Forensic Sci. Int., 2014, 244, 196.

18. A. B. Kanu, S. D. Brandt, M. D. Williams, N. Zhang, and H. H. Hill, Anal. Chem., 2013, 85, 8535.

19. E. de Rijke, P. Out, W. M. A. Niessen, F. Ariese, C. Gooijer, and U. A. T. Brinkman, J. Chromatogr. A, 2006, 1112, 31.

20. B. Voirin, Phytochemistry, 1983, 22, 2107.

21. Scientific Working Group for the Analysis of Seized Drugs (SWGDRUG), http://www.swgdrug.org/.

22. P. Roesner and T. Junge, J. Mass. Spectrom., 1996, 31, 1047.

23. F. Westphal, T. Junge, U. Girreser, W. Greibl, and C. Doering, Forensic. Sci. Int., 2012, 217, 157. 